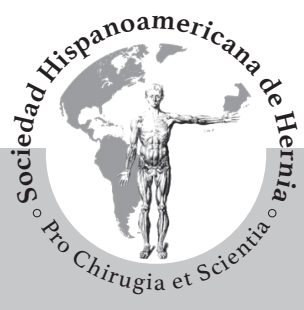

\title{
«Agresividad» de las hernioplastias inguinales. Inguinodinia e influencia de abordajes, técnicas y áreas críticas de riesgo neuropático. «Profilaxis»
}

\author{
"Aggressiveness" of groin hernioplasties. Inguinodynia \\ and influence of approaches, techniques and critical \\ areas of neuropathic risk. "Prophylaxis"
}

\section{David Dávila Dorta}

Hospital General Universitario. Hospital Vithas-Nisa 9 de Octubre. Valencia (España)

\section{Resumen}

Recibido: 28-05-2018

Aceptado: $31-05-2018$

\section{Palabras clave:}

Dolor crónico después de reparación de hernia inguinal, dolor inguinal posoperatorio crónico, dolor inguinal crónico neuropático, inguinodinia, invasividad de la hernioplastia inguinal, agresión tisular en la cirugía de la hernia inguinal.

El dolor inguinal posoperatorio crónico (somático o neuropático) es la secuela más frecuente, importante y limitante de la cirugía herniaria inguinal, cuya prevalencia exacta se desconoce. El trabajo expone, bajo una visión personal, sinóptica y objetiva, algunas connotaciones sobre la génesis de los tipos de dolor inguinal, especialmente el neuropático, generado por la agresión técnica (invasividad, disectividad y reparatividad), sobre áreas anatómicas específicas por las que discurren los correspondientes nervios inguinales periféricos, expuestos a riesgos neurolesivos por posibles maniobras inapropiadas.

Para mejorar la comprensión de la agresividad tisular y de la posible potencialidad neurolesiva de las técnicas hernioplásticas, se aportan 2 clasificaciones (personales, inéditas, intuitivas y objetivas). La primera, relaciona a grupos y modelos hernioplásticos con la dimensión cuantitativa $(\mathrm{cm})$ y la extensión cualitativa de la invasividad (maxi, normo, mini o mínimamente invasivas), así como la extensión cualitativa (maxi, normo y minidisectivas) y la dimensión cuantitativa de la disectividad (superficie y volumen disectivo de técnicas abiertas y videoasistidas). La segunda clasificación relaciona a los mismos grupos y modelos técnicos con sus respectivas potencialidades neurolesivas sobre las respectivas áreas críticas de riesgo de dolor crónico neuropático, según el probable o improbable riesgo de lesionar determinados nervios en dichas áreas anatómicas, identificando además el posible efecto profiláctico que pudieran ejercer algunas de las opciones técnicas en la prevención del dolor crónico neuropático. Sin duda, es la experiencia, la pericia y la maestría técnico-científica del cirujano, la mejor profilaxis de la inguinodinia.

\section{Abstract}

Chronic postoperative inguinal pain (somatic or neuropathic) is the most frequent, important and limiting sequela of inguinal hernia surgery, whose exact prevalence is unknown. The work exposes, under a personal, synoptic and objective view, some connotations about the genesis of the inguinal pain types, especially the neuropathic, generated by the technical aggression (invasiveness, dissectivity and reparativity), on specific anatomical areas through which they run the corresponding peripheral inguinal nerves, exposed to neurolesive risks by possible "inappropriate" maneuvers.

To improve the understanding of tissue aggressiveness and the possible neurolesive potential of hernioplastic techniques, 2 classifications (personal, unpublished, intuitive and objective) are provided. The first one relates to hernioplastic groups and models with the quantitative dimension $(\mathrm{cm})$ and the qualitative extension of the invasiveness (maxi, norm, mini or minimally invasive), as well as the qualitative extension (maxi, norm and minidisective) and the quantitative dimension of the dissectivity (surface and dissective volume of open and video-assisted techniques). The second classification relates to the same groups and technical models with their respective neurolesive potentials on the respective critical areas of risk of chronic neuropathic pain, according to the probable or unlikely risk of damaging certain nerves in said anatomical areas, also identifying the possible "prophylactic" effect "That could exercise some of the technical options in the" prevention "of chronic neuropathic pain. Undoubtedly, it is the experience, the expertise and the technical-scientific expertise of the surgeon, the best prophylaxis of inguinodynia.

Chronic pain after inguinal hernia repair, chronic postoperative groin pain, chronic neuropathic groin pain, inguinodynia, invasive groin hernioplasty, tissue aggression in groin hernia surgery.

*Autor para correspondencia: David Dávila Dorta. Hospital Vithas-Nisa 9 de Octubre. C/ Valle de la Ballestera, 59. 46015 Valencia (España) Correo electrónico: ddavila@sohah.org

Dávila Dorta D. «Agresividad» de las hernioplastias inguinales. Inguinodinia e influencia de abordajes, técnicas y áreas críticas de riesgo neuropático. «Profilaxis». Rev Hispanoam Hernia. 2018;6(4):167-179

Este artículo se presentó como ponencia en mesa redonda: Dolor Inguinal. Profilaxis del dolor inguinal. Reparación preperitoneal por vía posterior abierta. Ponencia al II Curso de Actualización en Cirugía de Pared Abdominal. Sociedad Hispanoamericana de Hernia (SoHaH). 17, febrero 2017, Bilbao. 


\section{Introducción}

El dolor inguinal posoperatorio crónico (DIPC) se ha convertido en las últimas décadas de forma progresiva y contumaz, en la secuela, quizás, más preocupante de la cirugía herniaria, con promedios del $10 \%-18 \%(0.7 \%-75 \%)^{1-3}$ superando en prevalencia a la recidiva, cuyos promedios siguen oscilando entre el $10.5 \%-3.3 \%$ (0.5 \%-30 \% $)^{4,5}$. Solo en PubMed, Chronic pain after inguinal hernia repair contabiliza 474 artículos desde el año 1982 al 2017. Extrapolándolos a la década 2013-2023, las publicaciones ascenderían a 662 (fig. 1), y sumarían algunos millares más si se publicasen los artículos de revistas no indexadas, monografías, capítulos de libros, conferencias y comunicaciones a congresos. ¡Y aún son decenas de miles los cirujanos que ni publican ni informan de sus resultados! ¿Cuál es la prevalencia real del DIPC y del dolor inguinal posoperatorio crónico neuropático (DIPCN)? Actualmente, la respuesta sigue —y seguirásiendo incontestable.

La génesis del dolor inguinal posoperatorio agudo (DIPA), es simple de entender en todos los operados, pero se torna compleja en algunos de ellos por que la afectación tisular y/o neural, intray posoperatoria precoz puede, en ocasiones, verse agravada por ciertas características del paciente, ajenas a la cirugía ${ }^{6}$, pero casi siempre relacionadas con ella: abordajes, técnicas, experiencia y habilidad del cirujano ${ }^{7}$. Factores, estos últimos, determinantes en la producción del constante dolor inguinal posoperatorio agudo somático (DIPAS) y del variable (DIPCN), motivos de la ponencia, inguinodinia, presentada en Bilbao $^{8}$, y razón de este artículo.

Desde las primitivas ortodoxas reparaciones herniarias ${ }^{9,10}$ hasta la diversidad de técnicas derivadas, se asume que las herniorrafias son más dolorosas que las subsecuentes hernioplastias con malla y estas, a su vez, más o algo más dolorosas que el generado por las ulteriores hernioplastias videoasistidas, nacidas con la pretensión de reducir el DIPAS y anular la recidiva y el DIPCN. La prueba del tiempo parece justificar la primera premisa pero no las siguientes, sujetas a continuos debates y controversias en la bibliografía, como p. ej. expresa la figura 2 , en 1370 pacientes, y la figura 3 mediante rigurosos modelos estadísticos, en 5404 pacientes ${ }^{11-13}$.

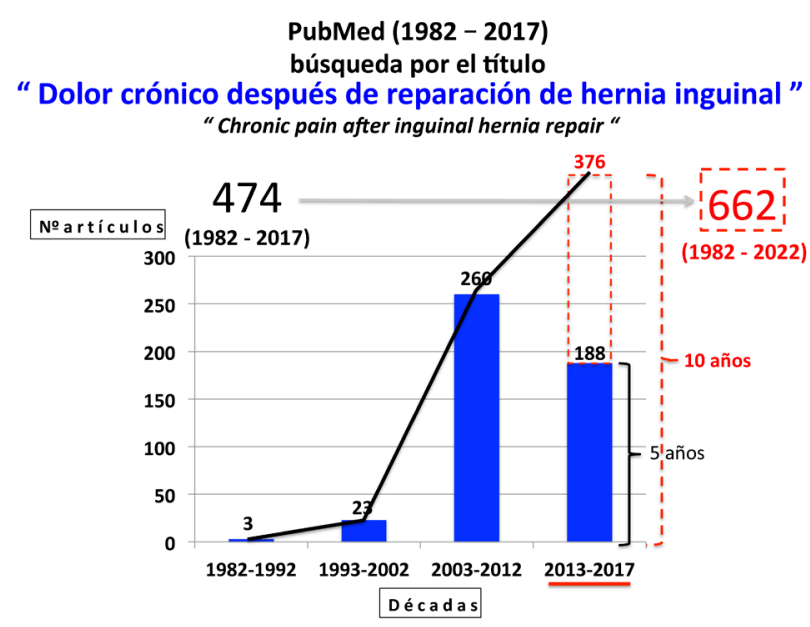

Figura 1.
Por ello, este trabajo tratará de exponer, bajo una visión personal, sinóptica y objetiva, algunas connotaciones sobre la génesis del DIPAS, del dolor inguinal posoperatorio crónico somático (DIPCS) y el DIPCN en relación con la agresión anatómica ejercida sobre los tejidos y las áreas críticas de riesgo de dolor inguinal posoperatorio crónico neuropático (ACRDIPCN), por los abordajes y técnicas hernioplásticas, aportando además algunas observaciones y aclaraciones que puedan mejorar la comprensión de la potencialidad técnico-neurolesiva de la cirugía herniaria, e incluso identificar el posible efecto profiláctico que pudieran ejercer algunas hernioplastias en la prevención del DIPCN.

\section{¿Por qué se produce dolor inguinal tras la reparación de una hernia?}

El dolor se produce en la ingle, como en cualquier otra parte del organismo, por la activación de los nociceptores del tejido agredido, foco del que parten estímulos dolorosos a través de vías nerviosas de corto recorrido hasta la médula espinal, donde completarán los arcos reflejos de respuesta defensiva inmediata. Mientras, por otras vías de largo recorrido, la espinotalámica y la espinoreticular, esos nociestímulos ascienden al tálamo y al sistema límbico, núcleos proyectores de la información nociceptiva, entre otras, hacia la corteza cerebral, sintetizadora, moduladora y efectora de la subjetiva percepción nocicepetiva del dolor a través de una serie de respuestas elaboradas, coordinadas y reguladas por otras vías nerviosas descendentes que, con celeridad, telecomandan otro grupo de respuestas biológico-proteccionistas dirigidas al tejido dañado y a diversos sistemas del organismo, elaboradores y/o colaboradores de las respuestas fisiológico-defensivas frente al trauma tisular, mediadas por el síndrome general de adaptación ${ }^{14-19}$.

Pasado el efecto de la anestesia tras la reparación herniaria, el paciente comienza a percibir el DIPAS originado por el traumatismo de los tejidos incindidos, disecados y reparados. Sin embargo, en algunos enfermos además de prolongarse el DIPAS, pueden percibir otro distinto, más intenso, quemante, intermitente o continuo, por una lesión neural añadida en algún sector

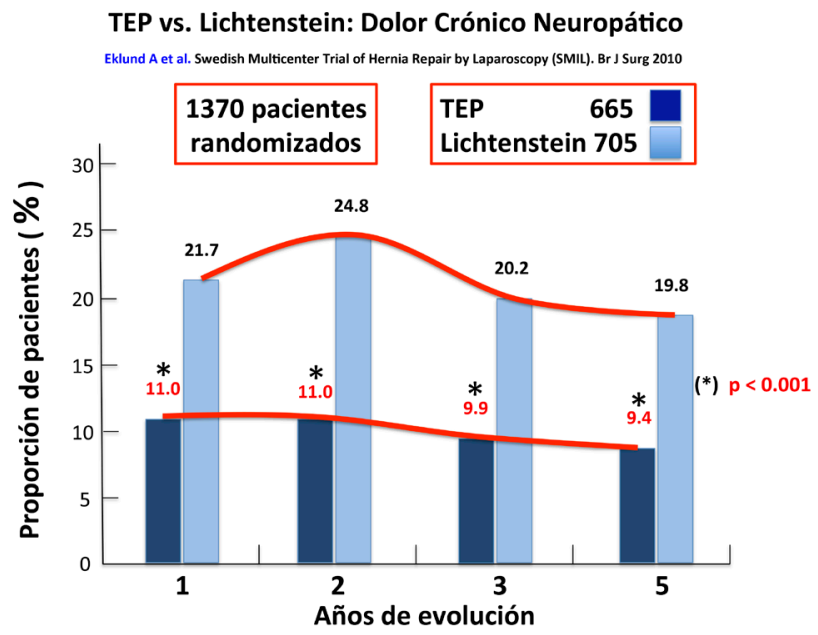

Figura 2. 
The Totally Extraperitoneal Method versus Lichtenstein's Technique for Inguinal Hernia Repair: A Systematic Review with Meta-Analyses and Trial Sequential of Randomized Clinical Trials. Koning GG et al. PLoS One. 2013;8 (1):e52599

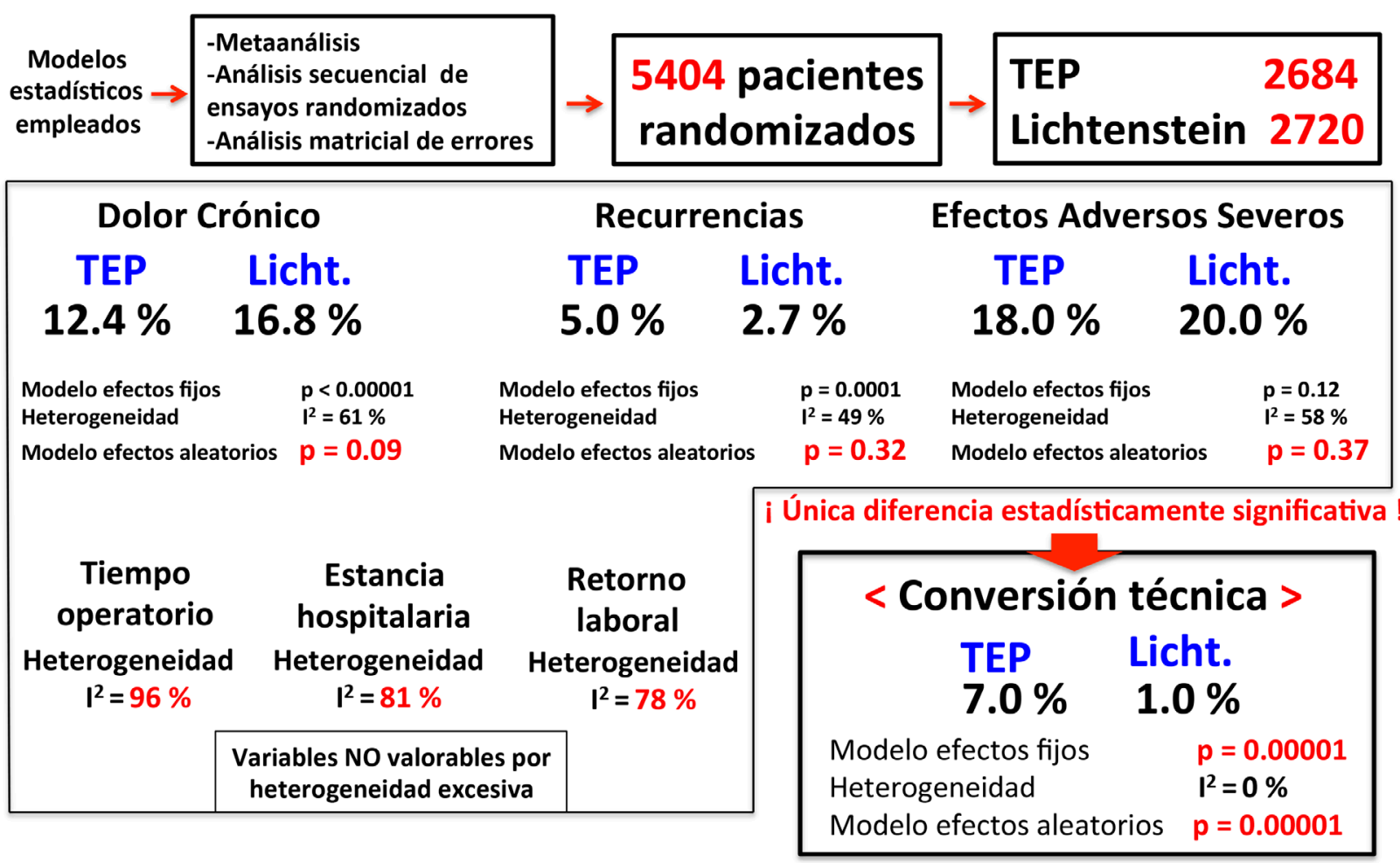

Todavía existe un riesgo considerable de que la ventaja del procedimiento TEP sugerido por el modelo de efectos fijos, ignorando la gran heterogeneidad, pueda ser el resultado combinado de sesgos y errores aleatorios.

Figura 3.

del trayecto anatómico, en su correspondiente ACRDIPCN, como se describirá más adelante. Dolor de curso solapado, o independiente del DIPAS, que debutará y evolucionará hacia un DIPCN, y originado:

1. En un segmento del trayecto de alguno de los nervios periféricos procedentes de las ramas espinales del plexo lumbosacro, destinadas a la región inguinal, genital, femoral y zona proximal antero interna del muslo.

2. En las zonas más periféricas de estos nervios - fascículos cutáneos de las regiones autónomas-, o en sus fibras terminales dermocutáneas de uno, o casi siempre de dos de estos nervios, donde se entrecruzan sus fibras terminales delimitando las áreas neuroanatómicas de solapamiento dermocutáne ${ }^{20}$ (fig. 4), en las que es infrecuente el DIPCN pero habitual el DIPAS, además de posibles parestesias, disestesias, alodinias, etc.

Cada nervio periférico se distribuye por un área anatómica inguinal específica en la que existen frecuentes variaciones topográficas del trayecto hasta en un $60 \%$, y/o de la división de sus fascículos - nervio único o bifurcado- en casi el $22 \%$, o la sobreangulación del nervio ilioinguinal (NII) próxima al orificio superficial en el $15 \%$, etc., variabilidad que exige del cirujano el correcto conocimiento neuroanatómico inguinal, y la destreza téc-

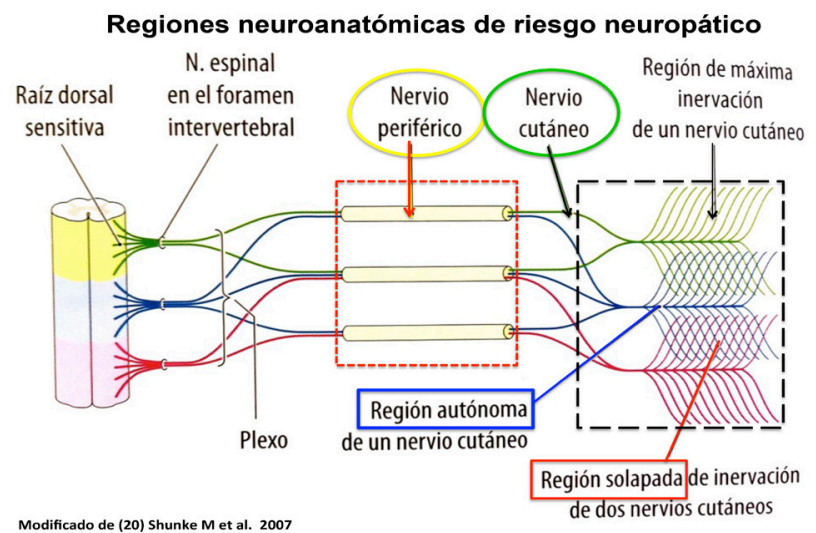

Figura 4. Nervios espinales periféricos y zonas-segmentos de riesgo neurolesivo.

nica para identificar con precisión esas zonas críticas expuestas al riesgo neurolesivo ${ }^{21-26}$, casi siempre por disecciones inapropiadas, electrocauterios, desgarros, puntos, grapas, mallas, etc. durante algunas de las tres etapas técnico-anatómicas, secuenciales de la cirugía herniaria ${ }^{27}$ : 
1. Invasiva: por la dimensión de la incisión y penetración parietal en la piel, tejido celular, aponeurosis y, eventualmente, músculos, según la opción técnica utilizada.

2. ${ }^{\text {a }}$ Disectiva: por la magnitud de la disección tisular necesaria para la identificación y exposición en el campo operatorio de las estructuras músculos-fasciales, vasculares, nervios inguinales en sus respectivas ACRDIPCN, cordón espermático (o ligamento redondo en la mujer) y sacos herniarios. Pasos disectivos de dimensiones variables (técnica y técnico-dependientes), se aborde la ingle por vía anterior, posterior abierta o por la videoasistida.

3. a Reparativa: durante el tratamiento del defecto herniario, mediante suturas directas, plastias con los propios tejidos, o con apoyo de mallas: sin fijación o fijada con puntos, grapas, pegamentos sintéticos, o empleando mallas autoadhesivas.

El DIPAS, pues, es la consecuencia de los efectos técnico-lesivos producidos en estas 3 etapas, y motivado por la respuesta local, biomolecular inflamatoria, fisiológica ${ }^{17,18}$ de la que, una vez finalizada la anestesia, emerge su percepción nociceptiva, en ausencia de otros factores añadidos de dolor somático o de lesiones neurales. El proceso reparativo-cicatricial puede prolongarse hasta el tercer $\mathrm{mes}^{28}$, incluso continuar como dolor somático — sin componente neuropático - por una respuesta inflamatoria anómala: rechazo de mallas, infecciones, suturas a tensión, granulomas, etc. O bien, establecerse posteriormente como dolor neuropático: adherencias de la malla o tapón a un segmento de uno o más nervios periféricos, desprotegidos o lesionados durante la disección por atrapamiento o sección por ligaduras, grapas, etc. transformándose en DIPCN a partir del tercer mes, ya como secuela establecida ${ }^{29,30}$.

\section{¿Qué características tiene el dolor inguinal poshernioplastia?}

El DIPAS, percepción nociceptiva del trauma generado por la reparación herniaria, motiva una respuesta refleja biológico-defensiva del organismo frente al daño tisular, fenómeno común en el hombre y en gran parte de la escala filogenética ante cualquier estímulo físico, químico, térmico o biológico. El paciente lo percibe de forma inmediata, durante el posoperatorio precoz, con una intensidad variable que disminuye entre el $2 .^{\circ}$ y $10 .^{\circ}$ día del posoperatorio, aunque en algunos casos persiste durante semanas en franca disminución, hasta el $3 .^{\text {er }}$ mes, en función de la favorable respuesta biológico-cicatricial. Etapa en la que puede acompañarse de forma simultánea y solapada de un dolor neurítico precoz y agudo, de intensidad variable y de presentación confusa y desconcertante que, ocasionalmente, acaba en DIPCN ${ }^{32}$. El tratamiento del DIPAS se dirigirá siempre a la causa que lo motivó: la agresión tisular. Y son los analgésicos los que logran casi siempre su disminución o anulación, cooperados por la sistemática respuesta general orgánica a la agresión ${ }^{15,33}$.

El DIPAS está influido por la edad, sexo, estado físico, antecedentes patológicos, ansiedad, nerviosismo, tratamientos neuropsiquiátricos, etc. ${ }^{31}$ pero, especialmente, por la agresión de abordajes y técnicas empleadas. No existe relación directa entre la intensidad del DIPAS, generado por el abordaje, con el producido por la extensión de la disección y la reparación del defecto, se opere por cualquier vía, salvo que se produzca una lesión de un nervio periférico a nivel de su ACRDIPCN. También existe relación entre el DIPAS y la longitud del abordaje $\mathrm{e}^{34}$ : la tensión generada en la herida es proporcional al cuadrado de su longitud, siendo la suma de las longitudes parciales de las incisiones cortas y la suma de sus tensiones respectivas, menor que la tensión producida por una herida única de la misma longitud. Es más, en cirugía videoasistida, el DIPAS disminuye cuando la incisión lineal para la introducción del trocar se amplía 1.2 veces su diámetro externo para el correcto ajuste. Paradójicamente, el trocar multipuerto tipo SILS en la hernia inguinal produce un daño $30 \%$ superior al que producen los 4 puertos en una colecistectomía laparoscópica ${ }^{34-36}$. De ahí la importancia para el cirujano del preciso conocimiento técnico y neuroanatómico de las ACRDIPCN en los distintos abordajes y técnicas como ya se describirá, con el fin de reducir aún más, si cabe, el riesgo neurolesivo en sus trayectos inguinales: esta sería la correcta profilaxis del DIPCN, evitando así las gratuitas y selectivas, o sistemáticas, neurectomías intraoperatorias profilácticas ${ }^{37}$, salvo por imperativos técnicos.

La perpetuación del DIPAS puede conducir al DIPCS, o transaformarse en DIPCN. El primero, prolongado en el tiempo, cursa con remisiones y puede superar ampliamente el $3 .^{\circ}$ mes de posoperatorio: cicatrices, recidiva herniaria, malloma, etc. con una semiología relativamente benévola que, en bastantes ocasiones resuelve la cirugía. Por el contrario, el dolor inguinal posoperatorio agudo neuropático (DIPAN) aparece tras una lesión neural intra- o posoperatoria manifestada siempre de forma aguda e intensa de principio, exigiendo una exploración quirúrgica inmediata que identifique y resuelva el daño neural por atrapamiento - grapas, puntos, malla, etc.-. O puede evolucionar como un aparente DIPCS, poco mitigable, que persiste o se intensifica con el tiempo superando el 3 .r $^{\text {er }}$ mes, incluso hasta años después, con refractariedad a las terapias aplicadas y con una evolución clínica independiente del proceso fisiológico-cicatricial, transformado en complicación quirúrgica, ya secuela neuropática ${ }^{1,3,6,38,39}$ que debe inducir a una seria y profunda reflexión por las consecuencias: desequilibrio psicofísico, deterioro de la movilidad, de la actividad laboral, social y familiar, y por la continua dependencia médico-sanitaria ante la escasa respuesta terapéutica, etc. Situación que exige con precocidad un diagnóstico etiopatogénico y topográfico mediante estudios neurofisiológicos, radiológicos y, particularmente con el test del mapeo inguinal por dermatomos de Álvarez Quintero ${ }^{40}$, exploración sencilla y notablemente diagnóstico-costo-efectiva para la decisión terapéutica, casi siempre la neurectomía quirúrgica abierta o videoasistida, cuyos resultados son aceptablemente satisfactorios ${ }^{41,42}$.

\section{¿Se puede realizar profilaxis del dolor poshernioplastia?}

En la cirugía de la hernia se producen 2 circunstancias conceptual y temporalmente distintas al aplicar stricto sensu los términos «profilaxis» y «tratamiento» del dolor inguinal posoperatorio:

$1 .^{\text {a }}$ : en el DIPAS sería incorrecto hablar de profilaxis del dolor posoperatorio desde el inicio hasta el final de la anestesia pues, el dolor es esencia connatural del acto quirúrgico y los analgésicos no evitan que se generen los estímulos nociceptivos desde los tejidos agredidos, ni tampoco su 
percepción dolorosa. Solo es posible evitarlo mediante el bloqueo anestésico — general, regional o local—durante el tiempo operatorio, aunque a veces, intencionadamente, es prolongable al despertar, o al posoperatorio inmediato, administrando anestésicos por vía raquídea (catéter), intravenosa (bomba), o local, impregnando los tejidos disecados, aunque algunos ${ }^{43}$ no encuentran diferencias estadísticamente significativas del dolor a las 4 h y 24 h aplicándola en el espacio preperitoneal disecado tras la TEP, o lo habitual, infiltrando las heridas ${ }^{44,45}$. Mientras continúe el efecto anestésico persistirá el bloqueo nociceptivo y perceptivo del dolor, efecto obviamente no conceptuable de «profilaxis posoperatoria del dolor». Solo una vez iniciada la reversibilidad anestésica, cuando aparece la desorientación, somnolencia y la incipiente percepción dolorosa ${ }^{46}$, será el momento de iniciar la verdadera profilaxis del DIPAS ${ }^{6}$ con los analgésicos adecuados y por las vías que procedan (iv, catéter, bomba, etc.), para amortiguar o eliminar el fisiológico y progresivo aumento de la intensidad perceptiva del dolor, mitigable casi siempre en los primeros días, a veces en semanas, o hasta en el plazo establecido de 3 meses.

2. a. cuando el DIPAS es resistente a la analgesia y supera el 3 . $^{\text {er }}$ mes se transforma en DIPCS, debido a lesiones tisulares no neuropáticas provocadas por puntos de sutura, mallas, granulomas, rechazo, etc.; y el tratamiento suele ser quirúrgico: extirpación de grapas, mallomas, adherencias, cicatriz, hidrocele, etc. Pues, la profilaxis solo hubiese sido posible evitando manejos disectivo-reparativos inapropiados, puntos o grapas incorrectas en número o sobre áreas sensibles, etc.

3. a : y en otros pacientes, el dolor refractario a la analgesia, tam-

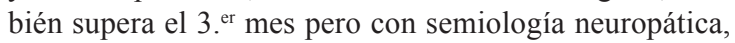
emergida de principio o solapada al dolor somático, por una lesión neural inadvertida, o inevitable, durante la hernioplastia, transformándose en DIPCN, una secuela que, oscila al menos entre el $10 \%-18 \%$ de las hernioplastias ${ }^{1-3}$. Es rebelde

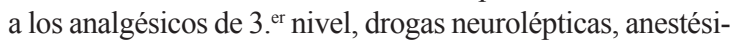
$\cos$ locales o regionales, radiofrecuencia, neurolisis química $y$, en ocasiones, a la cirugía ${ }^{6}$. Situación que precisa un diagnostico neurotopográfico, concretamente, mediante el mapeo inguinal por dermatomos ${ }^{40}$, junto a una obvia recapitulación clínica sobre los posibles factores etiopatogénicos generales, coadyuvantes, que han podido facilitar esa exagerada percepción dolorosa: antecedente de dolor inguinal preoperatorio, ansiedad, depresión, excitabilidad, predisposición genética, etc. ${ }^{6,31,47} \mathrm{y}$, específicamente, el tipo de abordaje, opción técnica empleada ${ }^{48-55}$, calidad técnico-operatoria y habilidad y experiencia del cirujano ${ }^{56}$, factores decisorios sobre qué tratamiento posoperatorio (no profilaxis) podría ser el técnicamente aplicable y más efectivo ${ }^{1-3}$.

Sin embargo, stricto sensu, sí es posible establecer la profilaxis del DIPCN:

\section{Profilaxis quirúrgica.}

Neurectomía intraoperatoria expresa: evitaría que se produzca el dolor posoperatorio realizando, paradójicamente, la neurectomía intraoperatoria intencionada de alguno, o de los 3 nervios periféricos inguinales: nervio iliohipogástrico (NIH), NII y rama genital (RG) del nervio genitofemoral (NGF). Son neuromutilaciones preventivas, alejadas de la ortodoxia anatomo-fisiológica y técnico-quirúrgica para cualquier hernioplastia. Dada la prevalencia, crudeza clínico-evolutiva y las consecuencias colaterales del DIPCN, convendría asumirlo en el $1 \%$, o quizás menos, siendo aconsejable, o autoexigible en tales casos, como lo fue y sigue siendo con la recidiva, perfeccionar o modificar la técnica habitualmente empleada, analizar y emplear otra opción con menor riesgo de inguinodinia o, remitir las hernias a cirujanos expertos o unidades especializadas de pared para minimizar esta grave secuela y las pretendidas preventivas y gratuitas neurectomías profilácticas, salvo excepciones ${ }^{37,57-59}$.

2. Profilaxis conservadora.

Conocimiento neuroanatómico y dominio técnico de las $A C R D I P C N$ : en todas las hernioplastias existe un riesgo de DIPCN superior al $10 \%^{1-3,50}$, al exponer en áreas neuroanatómicas específicas a determinados nervios inguinales que discurren por ellas, o a las ocasionales variaciones de trayectos o bifurcaciones ${ }^{21-26}$, cuyo conocimiento es imperativo para operar cualquier tipo de hernia por cualquiera de los abordajes y técnicas, con seguridad en el manejo técnico y profiláctico del DIPCN, como se muestra seguidamente.

\section{¿Qué son las áreas críticas de riesgo de dolor inguinal posoperatorio crónico de origen neuropático (ACRDIPCN), y cuáles son sus relaciones con los abordajes y las técnicas hernioplásticas?}

Son áreas anatómicas inguinales específicas con riesgo lesivo de los nervios periféricos que discurren por ellas durante los abordajes y las técnicas, y habitualmente relacionados con posibles disecciones inapropiadas ${ }^{28}$ durante la invasividad, disectividad y reparatividad herniaria. Para una comprensión más objetiva y didáctica de lo que supone la dimensión de la invasividad y la extensión de la disectividad, se han clasificado abordajes y técnicas con los prefijos maxi, normo y mini $^{27}$ (fig. 5), adjetivaciones que reconocen y distinguen de forma intuitiva, qué grado o

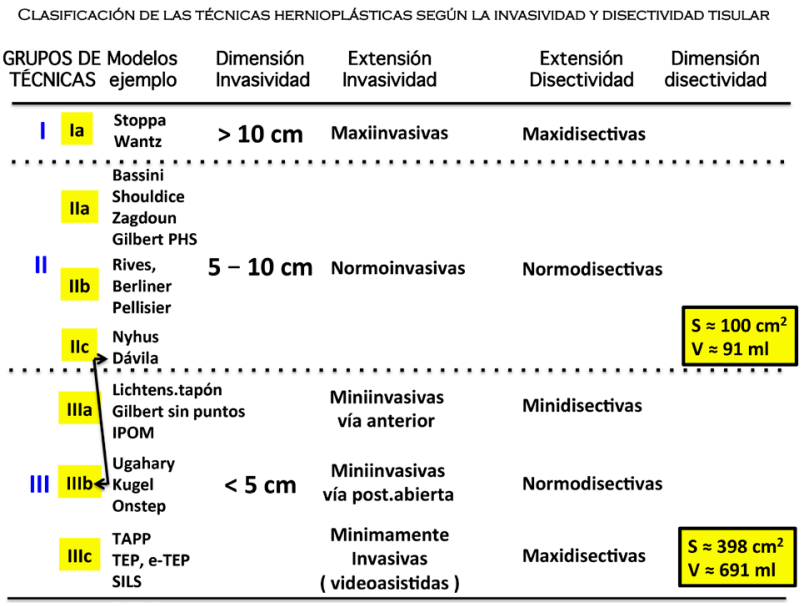

Figura 5. 
dimensión de invasividad y disectividad poseen y caracterizan a las hernioplastias más usuales, y a sus posibles equivalentes, con una notable aproximación a la realidad. A su vez, abordajes y técnicas son identificadas con sus respectivas ACRDIPCN y correspondientes nervios periféricos (Fig. 6) según el probable o improbable riesgo técnico neurolesivo, como se resume a continuación $22-27,60-62$ :

\section{Técnicas tipo I (abordajes $>10 \mathrm{~cm}$ )}

\section{Maxiinvasivas / Maxidisectivas}

Ia. Vía posterior abierta

- Técnica de Stoppa: es la más agresiva de las hernioplastias por la necesaria maxiinvasividad incisional y maxidisectividad tisular. El abordaje por línea media carece de ACRDIPCN, siendo improbable el riesgo de lesión del NIH y NII, mientras que el acceso preperitoneal es muy extenso por la obligada disección extraperitoneal bilateral, exponiendo las ACRDIPCN de la RG y RF del NGF, el NGF, y lateralmente, con infrecuencia, las ACRDIPCN del nervio femorocutáneo lateral (NFCL) $\mathrm{y}$, aún más lateral, la del NII.

- Técnica de Wantz: es prácticamente un «hemi-Stoppa» pero a través de un abordaje suprapúbico transverso-lateral más amplio que el de Nyhus. Sus ACRDIPCN corresponden a los nervios NIH, NII, RG, RF y NGF.

\section{Técnicas tipo II (abordajes de 5-10 cm)}

\section{Normoinvasivas / Normodisectivas}

\section{IIa. Vía anterior}

- Técnicas de Bassini, Mac Vay, Shouldice, Zadgoun-Lichtenstein-, Gilbert, Rutkow-Robbins, etc.: las ACRDIPCN son las correspondientes a los trayectos de los NIH, NII y

\begin{tabular}{|c|c|c|c|c|}
\hline \multirow{2}{*}{\multicolumn{2}{|c|}{$\begin{array}{l}\text { CLASES DE } \\
\text { TÉCNICAS }\end{array}$}} & \multirow{2}{*}{$\begin{array}{l}\text { Modelos } \\
\text { ejemplo }\end{array}$} & \multicolumn{2}{|c|}{$\begin{array}{l}\text { ÁREAS CRITIICAS DE RIESGO DOLOR NEUROPÁTICO } \\
\text { EXPOSICIOON DE NERVIOS INGUINALES }\end{array}$} \\
\hline & & & RIESGO PROBABLE & RIESGO IMPROBABLE \\
\hline I & la & $\begin{array}{l}\text { Stoppa } \\
\text { Wantz }\end{array}$ & $\begin{array}{l}\text { RG, RF, NGF, } \\
\text { NIH, NII, RG, RF, }\end{array}$ & $\begin{array}{l}\mathrm{NIH}, \mathrm{NII}, \mathrm{NFCL}, \mathrm{NII} \\
\mathrm{NGF}, \mathrm{NFCL}\end{array}$ \\
\hline & Ila & $\begin{array}{l}\text { Bassini } \\
\text { Shouldice } \\
\text { Zagdoun-Lichtens. } \\
\text { Gilbert PHS }\end{array}$ & NIH, NII, RG & RF, NF, NFCL \\
\hline II & Ilb & $\begin{array}{l}\text { Rives, } \\
\text { Berliner } \\
\text { Pellisier }\end{array}$ & NIH, NII, RG & RF, NF, NFCL \\
\hline & IIc & $\begin{array}{l}\text { Nyhus } \\
\text { Dávila . . . . . }\end{array}$ & $\begin{array}{l}\text { NIH, NII, RG, RF } \\
\text { Rị } \ldots \ldots \ldots . .\end{array}$ & $\begin{array}{l}\text { NII, NGF } \\
\text { N!H, N!I. } \ldots \ldots \ldots .\end{array}$ \\
\hline & IIIa & $\begin{array}{l}\text { Lichtens.tapón } \\
\text { Gilbert sin puntos } \\
\text { IPOM }\end{array}$ & NIH, NII, RG & $\mathrm{NFCL}$ \\
\hline III & IIIb & $\begin{array}{l}\text { Kugel } \\
\text { Onstep }\end{array}$ & $\begin{array}{l}\text { NIH, NII, RG } \\
\text { NIH, NII, RG }\end{array}$ & $\mathrm{NFCL}$ \\
\hline & IIIc & $\begin{array}{l}\text { TAPP } \\
\text { TEP - SILS } \\
\text { e-TEP }\end{array}$ & $\begin{array}{l}R G, R F, N G F, N F \\
N \text { esp. IX - XI, RG, RF, NGF, NF }\end{array}$ & $\begin{array}{l}\text { NO, NFCL, NII } \\
\text { NO, NFCL, NII }\end{array}$ \\
\hline
\end{tabular}

Figura 6. la RG del NGF, expuestas en las hernias indirectas, directas y femorales. Los 2 últimos, especialmente durante la disección del cordón espermático, siendo improbable lesionar el ACRDIPCN del FCL.

\section{Normoinvasivas / Normodisectivas}

IIb. Vía anterior transinguino-preperitoneal (TIPP)

- Técnicas de Rives, Berliner, Shumpelick, Pellisier, etc.: las ACRDIPCN son las mismas del grupo IIa, sin riesgo de lesión neural añadida por esta vía, durante la ampliación disectiva hacia el limitado espacio preperitoneal, para mejorar el posicionamiento de la malla.

\section{Normoinvasivas / Normodisectivas}

IIc. Vía posterior abierta

- Técnicas de Nyhus, Mc Evedy, Rignault, etc.: el abordaje es suprapúbico transverso-lateral, y el acceso preperitoneal, a través de una amplia incisión transversa de toda la musculatura plana que, una vez tratado el saco será suturada en bloque, sin o con malla de refuerzo. Las ACRDIPCN corresponden al $\mathrm{NIH}$, (la del NII es improbable por este abordaje), a la RG del NGF en el segmento preperitoneal del cordón espermático, y ocasionalmente, el ACRDIPCN de la RF del NGF.

- Técnica del autor ${ }^{60,61}$ : será descrita más adelante por ciertas particularidades técnicas que la diferencian del resto de abordajes abiertos y videoasistidos, y por el comportamiento técnico, versátil y polivalente y profiláctico frente al DIPCN.

\section{Técnicas tipo III (abordajes $<5 \mathrm{~cm}$ )}

\section{Miniinvasivas / Minidisectivas}

IIIa. Vía anterior

- Tapón de Lichtenstein (técnica original de Lichtenstein, no la popularmente conocida $\left.{ }^{63,64}\right)$.

- Tapón sin suturas de Gilbert ${ }^{65}$.

En ambas técnicas quedan expuestas las ACRDIPCN del NII y de la RG del NGF.

\section{Miniinvasivas / Normodisectivas}

IIIb. Vía posterior abierta

- Técnicas de Ugahary y de Kugel: son abordajes preperitoneales con riesgo lesivo de las ACRDIPCN del NIH durante la disección transmuscular, roma y casi a ciegas; del NII y de la RG del NGF durante la disección también casi a ciegas del cordón espermático y su tracción forzada a través del limitado abordaje. La disección roma preperitoneal, realizada también a ciegas, no ofrece riesgos neurolesivos. 
- Técnica Onstep: Es un abordaje mixto (vía preperitoneal y vía anterior). El abordaje y la disección es similar al de las dos técnicas previas, y también sus ACRDIPCN para el NIH y NII, añadiendo la exteriorización de la porción lateral de la malla - ya por vía anterior - cuyas bandeletas solapando al cordón espermático preinguinal generan el riesgo en las ACRDIPCN del NII y de la RG del NGF, común a las técnicas IIa por vía anterior.

- Técnica del autor: es miniinvasiva en 2/3 de los operados, como ya se explicará.

\section{Mínimamente invasivas / Maxidisectivas}

IIIc. Vía posterior vídeoasistida

- IPOM ${ }^{66}$ laparoscópica con prótesis intraperitoneal: riesgo improbable de lesión neural si los puertos se ubican en la línea medio-abdominal inferior. Durante la fijación abdomino-transperitoneal de la malla a la pared inguinal posterior se exponen las ACRDIPCN de la RG, RF, NGF, nervio femoral (NF) y NFCL.

- TAPP ${ }^{67}, T E P$, e-TEP ${ }^{68,69}$ y SILS $S^{70}$ son técnicas particularmente singulares por el evidente contraste entre la mínimamente agresividad invasiva frente a la olvidada maxiagresividad disectiva:

- Invasividad: mientras los abordajes se sitúen en la línea media se puede afirmar que carecen de ACRDIPCN — como también ocurre en la técnica de Stoppa - pues se mantienen alejados de los nervios periféricos, salvo que alguno de los puertos se aleje de la línea media, como ocurre en alguna variante de la TAPP y TEP y, por norma en la e-TEP, con el riesgo añadido de lesión neural por la penetración transmusculofascial, extraperitoneal, de los trócares sobre las ACRDIPCN de ramas anteriores de alguno de los nervios espinales IX, X u XI.

- Disectividad: durante la disección y reparación de la hernia en el obligado y sobredimensionado espacio preperitoneal, las ACRDIPCN se sitúan: medial al triángulo vascular de Doom — ajeno al tema de este artículo — el ACRDIPCN del nervio obturador (NO). Laterales, el triángulo «nervioso» del dolor, la superficie ocupada por las ACRDIPCN del NF, NGF y sus RG y RF, el NFCL — afectado hasta en el $2 \%$ de este tipo de hernioplastias - y ocasionalmente, aún más lateralmente, la del nervio $\mathrm{NII}^{71}$.

En definitiva, desde el punto de vista neuroanatómico y técnico quirúrgico son técnicas que precisan una disección maxiagresiva, objetivamente irrefutable, con un riesgo potencial de lesión neural superior al resto de técnicas. Obviamente, es bajo para cirujanos notablemente expertos ${ }^{11-13}$; moderado para cirujanos con pocas decenas de operaciones tuteladas, y de alto o muy alto riesgo para aquellos que, sin una curva de aprendizaje relativamente larga y controlada, intentan operar - sin la supervisión exigida o con tutores poco expertos-, guiados por el entusiasmo técnico-vanguardista y resultados triunfalistas, emanados de artículos, monografías, vídeos, etc.

\section{¿Por qué es desconocida o silenciada la dimensión de la agresión técnico-anatómica generada por la cirugía de la hernia inguinal?}

La reparación de la hernia inguinal tiene algunas peculiaridades técnico-quirúrgicas singularmente curiosas y paradójicas, que no se repiten en el resto de la cirugía general y del aparato digestivo, como son, por ejemplo:

1. Para tratar una hernia inguinal existen muchas técnicas, unas por vía anterior y otras por vía posterior abierta o videoasistida. Ninguna patología quirúrgica en cirugía general y del aparato digestivo tiene tal variedad de abordajes alternativos, y de opciones técnicas — históricas y actuales — para tratar cualquier tipo de hernia ${ }^{22-27,61,62}$.

2. En cirugía general y del aparato digestivo, cuando se opera cualquier patología (ajena a la hernia inguinal) por cirugía abierta o videoasistida, p. ej. colecistectomía, antirreflujo gastroesofágico, gastrectomía, colectomía, etc. mientras los pasos técnicos seguidos para la disección y la resección en ambas modalidades — abierta o videoasistida - son equivalentes, sí les diferencia la dimensión de los abordajes: el abierto es maxiinvasivo y el laparoscópico, mínimamente invasivo.

Sin embargo, en la cirugía de la hernia inguinal reparada por vía anterior o posterior abierta, el abordaje es normo- o miniinvasivo y la disección, normodisectiva en todas las técnicas, salvo en las de Stoppa y Wantz ${ }^{27}$ mientras que en la cirugía videasistida (TAPP,TEP, e-TEP, SILS...) siendo sus abordajes mínimamente invasivos —-mínimamente agresivos-, las disecciones preperitoneales generan una sobredimensionada superficie y volumen maxidisectivo - maxiagresivo-, bastante superior al producido por cualquiera de las opciones técnicas abiertas (fig. 7).

Por ello salta a la vista que estos conceptos de invasividad y disectividad están, sorprendente y frecuentemente fusionados, quizás confundidos por un olvido perceptivo-conceptual-diferencial entre ellos, siendo asumidos, interpretados, incluso defendidos a ultranza de forma equívoca, resultando por ello curioso, llamativo y paradójico que la percepción de esa irrefutable discordancia entre los que afirman y publican que las técnicas videoasistidas son mínimamente invasivas — ¡no agresivas!—, frente a la contraria e incuestionable evidencia de la sobredimensión disectiva — ¡maxiagresiva! — del espacio anatómico preperitoneal, necesaria para poder situar y asentar la malla. Datos y precisiones que ni se publican ni mencionan, y siguen considerándolas y divulgándolas como técnicas mínimamente invasivas, como si la evidente y objetiva maxiagresividad disectiva fuese ¡mínimamente agresiva!, olvidando o eludiendo referencia alguna al sobreextenso daño disectivo preperitoneal, aún pretendidamente menor para $\operatorname{otros}^{27,72}$, si la cirugía de la hernia es robótica-asistida. Quizás, entre otras razones, por la influencia de los sobrevalorados resultados posoperatorios.

Mas aún, las tasas de hernia recidivada y de DIPC (figs. 2 y 3 ) en estas técnicas videoasistidas, siguen siendo llamativamente altas, salvo excepciones, en publicaciones y metaanálisis ${ }^{4,11-13}$, y sin casi referencias a las graves, o muy graves complicaciones durante - y después - del largo rodaje técnico y, a las repercusiones quirúrgicas - obstaculizadoras-, a medio y largo plazo, para cirujanos, urólogos, vasculares, oncoginecólogos, etc. cuando intentan acceder al espacio preperitoneal por otras patologías ${ }^{73-79}$.

La maxidisección es objetivamente demostrable en la TAPP (la menos maxiagresiva de ellas) pues, tras la peritoneotomía transabdomino-inguinal perfila, grosso modo, una figura elipsoide en el espacio preperitoneal, fácilmente dimensionable, generando una superficie $\left(\mathrm{cm}^{2}\right)$ del $300 \%$ y un volumen (ml) del $700 \%$, (fig. 8) superior a las dimensiones obtenidas en las técnicas abiertas ${ }^{8}$, 

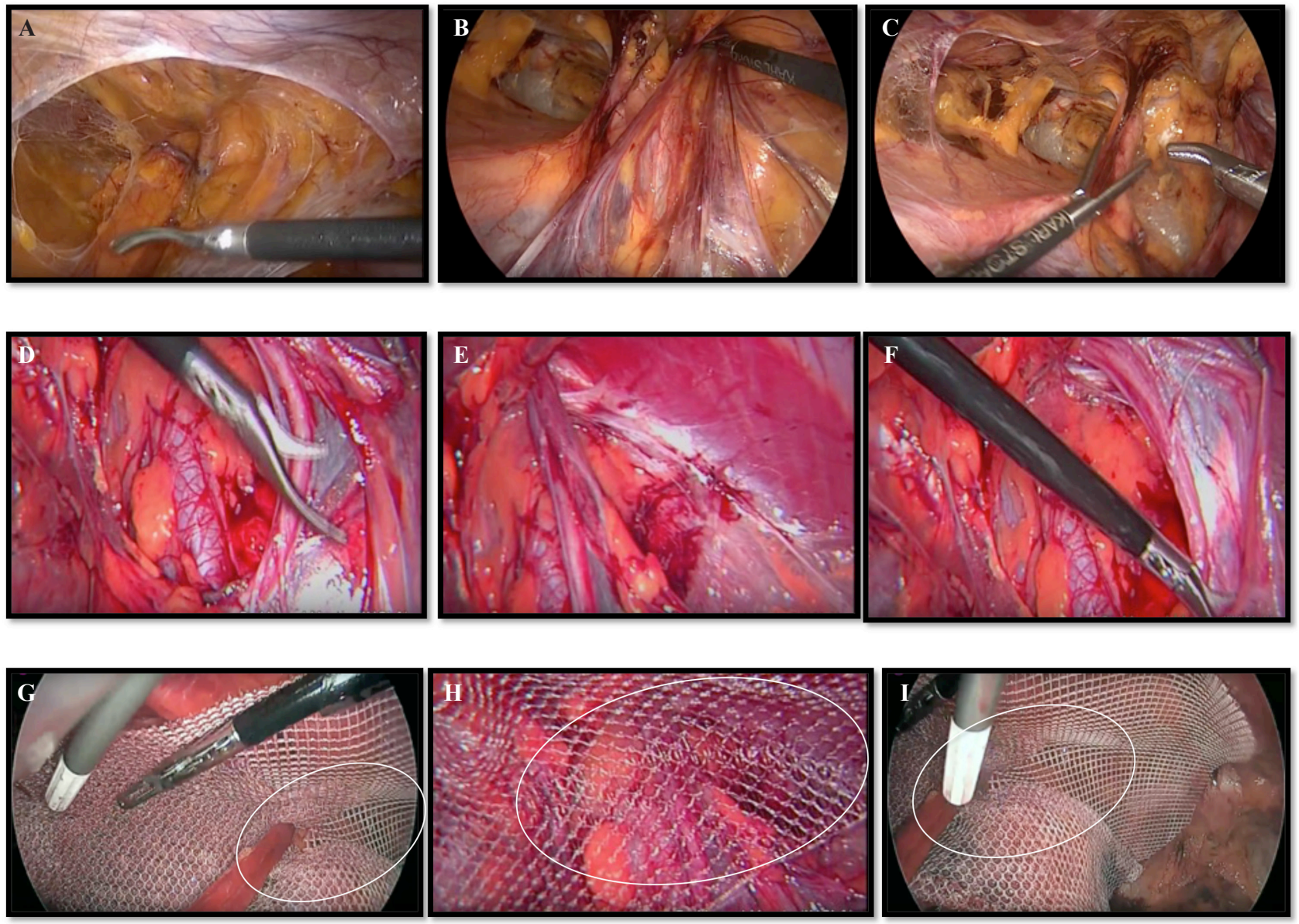

Figura 7. Nervios espinales periféricos y zonas-segmentos de riesgo neurolesivo.

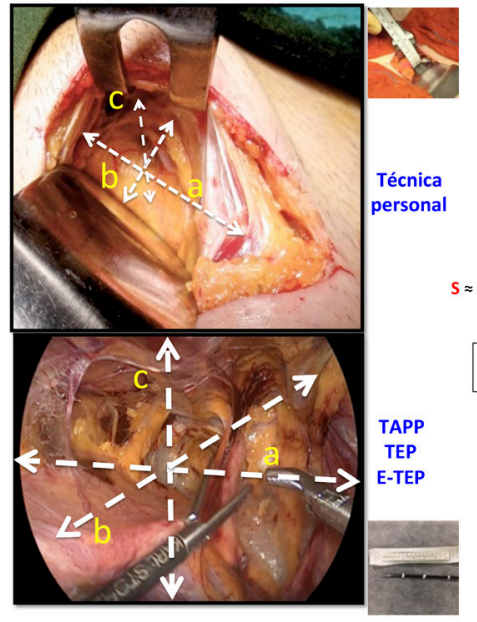

$(7 \mathrm{~cm} \times 5 \mathrm{~cm} \times 5 \mathrm{~cm})$

Superficie disecada

$S=100 \mathrm{~cm}^{2}$

Volumen de disección

$\mathbf{V}=91 \mathrm{ml}$

$S \approx 4 \pi\left[\left(a^{p} b^{p}+a^{p} c^{p}+b^{p} c^{p}\right) / 3\right]^{1 / p}$ y $V=4 / 3 \pi a b c$

$(15 \mathrm{~cm} \times 8 \mathrm{~cm} \times 11 \mathrm{~cm})$

Superficie disecada

$\mathrm{S}=398 \mathrm{~cm}^{2}$

Volumen de disección

$\mathrm{V}=691 \mathrm{ml}$

$S>300 \%$ y $V>700 \%$

Figura 8. Cuantificación comparativa de la dimensión disectiva inguinal, en superficie y volumen, entre una vía posterior preperitoneal abierta (técnica del autor) y el abordaje videoasistido TAPP.

como demuestran fotografías, vídeos y el mismo quirófano. La TEP genera dimensiones disectivas mayores que la TAAP, al sumar al elipsoide preperitoneal, la dimensión troncocónica resultante de la disección neumática desde el acceso subumbilical hasta el espacio preperitoneal. Dimensiones aún superadas ampliamente por la e-TEP, porque la superficie y el volumen disectivo troncocónico contabiliza desde uno de los hipocondrios (normalmente desde el derecho) hasta el común elipsoide disectivo preperitoneal de todas ellas ${ }^{8,69}$

Es llamativo que esa disectividad sobredimensionada sea todavía para muchos cirujanos, incluidos laparoscopistas disconformes o reticentes a utilizar cirugía videoasistida en la hernia inguinal, uno de los factores más poderosos de resistencia al empleo de este tipo de abordaje, junto al desconocimiento técnico-anatómico preperitoneal, a la prolongada y ocasionalmente peligrosa curva de aprendizaje y a unos resultados cuyas diferencias estadísticamente significativas, cuando las hay frente a determinadas técnicas abiertas, no terminan de traducirse en diferencias clínicas relevantes ${ }^{13}$. Contrasta, pues, el alto prestigio nacional e internacional de estas técnicas por sus resultados triunfalistas frente a una, todavía, reducida prevalencia global de empleo, lejos de las pretendidas expectativas auspiciadas y esperadas desde hace más de 2 décadas: las hernias se operan en Suecia por abordajes videoasistidos en el $30 \%$ de hombres y el $65 \%$ de mujeres; $40 \%$ en Australia, $10 \%$ en Italia y $7 \%$ en México ${ }^{80-85}$. 
La otra forma objetiva de dimensionar la invasividad, entendida esta, stricto sensu, como la agresión tisular derivada de la invasividad, disectividad y reparatividad de la cirugía herniaria ${ }^{27}$ es cuantificando el trauma tisular a través de marcadores plasmáticos de la respuesta inmunoinflamatoria, para evaluar y comparar sus posibles variaciones en relación con el nivel de daño tisular ocasionado por las hernioplastias abiertas y videoasistidas.

Algunos artículos demuestran que la hernioplatia para tratar las hernias recidivadas con la TEP produce menor respuesta inflamatoria que las abiertas ${ }^{86}$. Los pacientes tratados con hernioplastias protésicas tienen mayor concentración sérica de PCR e IL-6 que los con solo herniorrafias, siendo mayor el nivel de marcadores en la cirugía abierta que en la videoasistida ${ }^{87}$. La técnica de Stoppa genera mayor respuesta inflamatoria que la TEP, y esta, con menor dolor posoperatorio y tiempo de hospitalización ${ }^{88}$. Sin embargo, esos resultados no son la norma en la bibliografía ni reflejan con suficiente nivel de evidencia la relación causa-efecto pretendida o esperada, es decir, que la cirugía videoasistida, como mínimamente invasiva que es, no se comporta como mínimamente agresiva, como señalan esos estudios comparativos entre la cirugía abierta y la videoasistida ${ }^{89}$, incluso cuando la hernioplastia abierta lleve o no una malla ${ }^{90}$. En el mismo sentido, tampoco hallan diferencias estadísticamente significativas en la respuesta inflamatoria entre la técnica de Kugel y la TEP ${ }^{91}$. Incluso, con resultados contradictorios, p. ej. que la TEP produce mayor respuesta inmunoinflamatoria que la técnica de Shouldice ${ }^{92}$. Otros estudios muestran resultados heterogéneos y sorpresivos: la hernioplastia de Lichtenstein no ofrece ventajas sobre la herniorrafia convencional, desde el punto de vista de la respuesta inmunoinflamatoria y de reactantes de fase aguda ${ }^{93}$. Y lo contrario, todos los marcadores aumentaron significativamente más en la técnica de Lichtenstein que en la de Bassini, aunque la primera, produce menos dolor y una recuperación posoperatoria más rápida, asociada a una mayor respuesta inflamatoria, probablemente debido a la malla ${ }^{94,95}$. Es lógico pensar que las mallas de baja densidad produzcan menor respuesta inflamatoria y estrés oxidativo que las de alta densidad, por la menor cantidad de polipropileno ${ }^{96}$. Otro estudio randomizado señala que la técnica de Lichtenstein requiere más disección tisular hasta alcanzar el saco peritoneal que la técnica de Nyhus, TAPP y TEP, justificado - para los autores - por el aumento significativo del nivel de IL-6, pero sin diferencias estadísticamente significativas entre la TAPP y la técnica de Nyhus ${ }^{53}$; afirmación discordante con los hallazgos disectivos entre la técnica del autor y la TAPP, superándole esta en un $300 \%$ de superficie disecada y un $700 \%$ de volumen disectivo $8,27,60-62$.

Resultados, como se comprueba, muy heterogéneos y relacionables fundamentalmente con sesgos en los diseños, metodologías incompletas y empleo limitado de marcadores específicos de respuesta inflamatoria ${ }^{90,93,97}$, justificativos de las discordancias y contradicciones observadas que limitan o cercenan la evidencia científica que pretende sustentar que las técnicas videoasistidas desarrollan menor respuesta inmunoinflamatoria que las técnicas abiertas. El análisis objetivo demuestra que son técnicas mínimamente invasivas pero no mini, o mínimamente disectivas, sino todo lo contrario: ¡maxidisectivas-maxiagresivas!

En definitiva, los artículos evaluados sobre hernia inguinal muestran un número limitado de marcadores inmunoinflamatorios específicos y la ausencia de otros marcadores relevantes, lo que dificulta una cuantificación más precisa y específica de la agresión tisular global así como la interpretación de su fundamento biológico, mejorable si se evaluaran:

a) la respuesta inmunoinflamatoria tisular: leucocitos, proteína $\mathrm{C}$ reactiva (PCR), interleucinas (IL-1, IL-2, IL-10, IL-13, IL-14); factor de necrosis tumoral alfa (TNF $\alpha$ ), fibrinógeno, interferón gamma (IFN $\gamma), \alpha 1$-antitripsina...

b) la respuesta del tejido fibroconectivo-adiposo: proteoglucanos, elastinas, lamininas, serinaproteinasas, metaloproteinasas (gelatinasas, colagenasas, estromelisinas, etc.), Inflamasoma (NLRP, ANL, ALR, Caspasa-1 activada, IFN $\beta$, IL-1 $\beta$, IL-18, NF- $\kappa \beta . .$.$) .$

c) la respuesta endotelial: el endotelio es fisiológicamente un tejido biológicamente muy activo, precisamente ante cualquier trauma tisular (prostaciclinas, activador del plasminógeno, proteinas $\mathrm{S}$ y C, glicosaminoglicanos, fibronectinas, factores activadores de plaquetas, factor $\mathrm{V}$, y activadores de los factores V y XII, ELAM-1, ICAM-1, ICAM-2, factores estimulantes de colonias, óxido nítrico, endotelinas, etc.). Si los estudios utilizaran estos y algunos otros marcadores, sería posible comprender mejor el daño tisular global producido por las hernioplastias, con mayor precisión y bastante menor variabilidad - heterogeneidad - en los resultados, aproximándolos más a la compleja realidad de la respuesta inmunoinflamatoria, y no alejados —en opinión del autorcomo los hallados hasta el momento en la cirugía herniaria $^{98-102 .}$.

\section{El abordaje posterior preperitoneal abierto, ¿puede ser un avance en la proflaxis del DIPCN?}

Como ya se apuntó, la única profilaxis, sensu stricto, del DIPCN consiste en evitar la lesión intraoperatoria, directa o indirecta, de los nervios periféricos inguinales en sus ACRDIPCN ${ }^{8,103}$ durante la etapa invasiva, disectiva y reparativa del defecto herniario. Todas las técnicas, se aborden por cualquier vía, tienen un riesgo relativamente bajo, salvo excepciones, de que alguno de los nervios periféricos pueda ser irritado o lesionado. Tras analizar en las técnicas hernioplásticas más representativas, su invasividad tisular, sus ACRDIPCN y sus nervios periféricos (tablas I y II) se observa una notable similitud o coincidencia con los resultados obtenidos por Günal Ö et al. ${ }^{53}$ tras randomizar 160 pacientes en 4 grupos de técnicas: vía anterior (Lichtenstein), posterior abierta (Nyhus), posterior laparoscópica (TAPP) y posterior endoscópica (TEP), después de un seguimiento mínimo de 7 años. Comparan tiempos operatorios, respuesta inmunoinflamatoria y dolor a las 6 y $48 \mathrm{~h}$, hallando mejores resultados, con diferencias estadísticamente significativas, a favor de las técnicas preperitoneales frente a la vía anterior, y una notable semejanza de resultados entre la técnica de Nyhus y las videoasistidas, reconociendo que los abordajes preperitoneales se comportan menos invasivos y subrayando que el abordaje posterior abierto - Nyhus — se puede utilizar como procedimiento de rutina para reparar las hernias inguinales. Encuentran conclusiones similares tras hernioplastias inguinales recidivadas: la reparación endoscópica produce menos dolor que la vía anterior - y añaden — los cirujanos con más de 5 reparaciones por vía posterior preperitoneal abierta reducen el riesgo de neuropatía crónica ${ }^{104}$. Otros grupos ${ }^{105,106}$ empleando un abordaje preperitoneal posterior abierto, similar al del autor ${ }^{107,108}$, 
-empleado y publicado 22 años antes-, no encuentran prácticamente inguinodinias, (como en nuestra extensa serie), y sí ventajas sobre la vía anterior y la endoscópica TEP.

En ese sentido, el principio técnico del abordaje posterior preperitoneal abierto del autor, evolucionado después de dos centenares de reparaciones clásicas de Nyhus entre 1986-1989 ${ }^{107}$ le diferencian definitiva y favorablemente de la técnica original de Nyhus ${ }^{60,61,109}$ por una menor normoagresividad invasiva, disectiva y reparativa; recidivas del $7 \%$ al $0.3 \%$ y DIPCN del $4 \%$ a menos del $0.1 \%$, en más de 3400 reparaciones consecutivas de hernias primarias, recidivadas, electivas y urgentes. A continuación, la técnica es resumida y diferenciada de la de Nyhus:

1. Abordaje suprapúbico transverso-lateralizado más corto, bajo y estético, normoinvasivo $(5-10 \mathrm{~cm})$ en hernias voluminosas, complejas, urgentes o complicadas, y miniinvasivo $(<5 \mathrm{~cm})$ en más de $2 / 3$ de pacientes con hernias primarias, electivas y recidivadas.

2. Incisión transversa de la hoja aponeurótica anterior del músculo recto, sin extensión a la musculatura plana y sin riesgo sobre el ACRDIPCN del NIH.

3. Incisión longitudinal de la fascia transversalis, siguiendo el borde lateral del músculo recto (pararrectal) hasta casi el pubis, exponiendo el espacio de Bogros, sin riesgos para las ACRDIPCN del NIH y del NII.

4. Rechazo craneal de la grasa preperitoneal con una valva maleable, exponiendo el «área» de Fruchaud e identificando y disecando el cordón espermático — previo a su incorporación al conducto inguinal por el orificio inguinal profundoy los posibles sacos indirecto, directo y femoral, con especial facilidad en las hernias complejas o complicadas, y solo con un riesgo limitado en el ACRDIPCN de la RG del NGF. No se abre ni diseca ni reconstruye el conducto inguinal y en ningún momento de la disección tisular o de la sencilla colocación de la malla (nunca a ciegas), se agrede ninguna ACRDIPCN, ni se puede contactar o lesionar ningún nervio periférico (fig. 9).

5. La malla de polipropileno no precisa nunca de una sobredimensionada disección preperitoneal, imprescindible en las técnicas videoasistidas, pues, cubre sobradamente los 3 orificios herniarios ${ }^{61,109}$ —área de Fruchaud-. Se le fija al ligamento de Cooper, y su extremo proximal queda alojado un par de centímetros bajo los bordes de la incisión aponeurótica del músculo recto (sin suturarlos entre sí), funcionando así como incisión que es, de relajación, para amortiguar y eliminar tensiones aponeuróticas (fig. 10) ${ }^{61,108,109}$.

6. Por último, es una hernioplastia simplificada, de muy corto y fácil aprendizaje (aproximadamente 10 casos tutelados), con resultados tras seguimientos hasta 30 años, al menos equivalentes a cualquiera de las técnicas de vanguardia. En definitiva, es un diseño técnico-quirúrgico personal que elude todas las ACRDIPCN de los nervios inguinales periféricos, siendo solo ocasional y levemente vulnerable la RG del NF (16\% de orquialgias leves y transitorias derivadas de la disección de ciertos sacos oblicuos externos y lipomas preperitoneales) $)^{109,110}$. Por los resultados obtenidos con este modelo técnico, es factible, sin duda, asignarle un comportamiento preventivo o profiláctico del DIPCN entre otras ventajas.

Y finalizo. Pienso en la equivalencia de la cirugía actual de la hernia inguinal, con el grato recuerdo de la ocurrente, famosa y

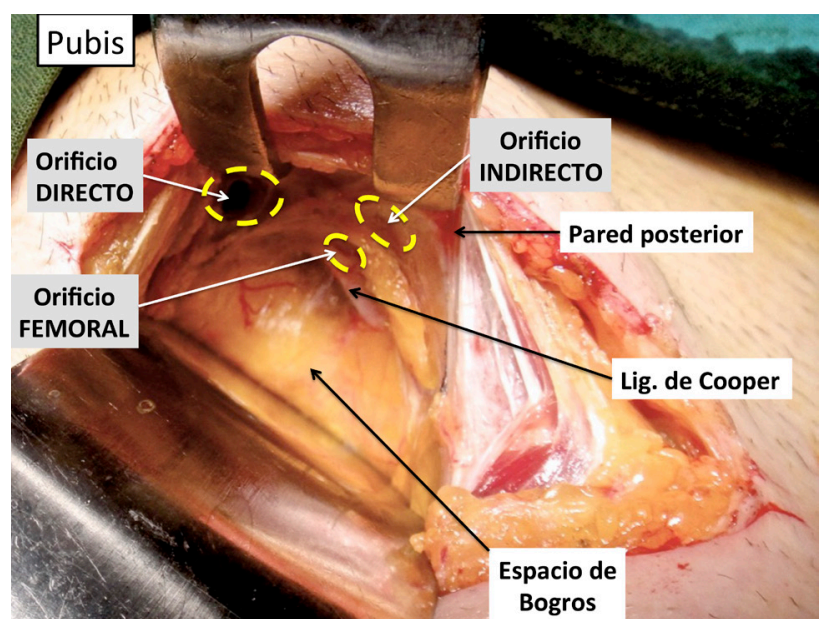

Figura 9. Técnica del autor. Espacio preperitoneal disecado, limitado y suficiente para cubrir los orificios inguinales («área» miopectinea de Fruchaud) con una malla. Visión anatómica suficiente y sin manipulaciones «a ciegas». No precisa la disección-identificación de ninguna estructura neurovascular de la ingle.
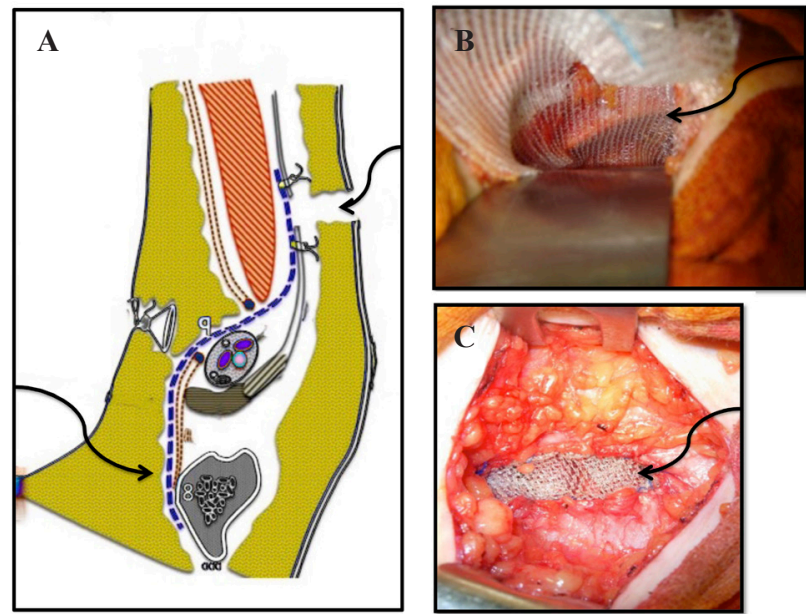

Figura 10. A. Esquema de un corte inguinal sagital de perfil. Posicionamiento de la malla (técnica del autor). B. Visión directa de la posición y extensión de la malla sobre la pared posterior inguinal. C. Detalle de la fijación del borde proximal de la malla. No se suturan los bordes aponeuróticos entre sí, sino a la malla = incisión de relajación + amortiguación de tensiones.

clarividente frase que pronunció Charles Mayo, en el American Medical Association Meeting de 1927 en Nueva York: «Si cualquiera quisiera cortar la mitad de mi estómago sano para curar una pequeña úlcera en mi duodeno, correría más rápido que él: $Q u o$ vadis, quo imus. A reflexionar.»

\section{Conclusiones}

En cualquier hernioplastia abierta o videoasistida, la profilaxis más efectiva del DIPCN radica en el conocimiento neuroanatómico de las ACRDIPCN de los nervios periféricos, la meticulosa 
disección ¡visual! de planos quirúrgicos y estructuras anatómicas, la identificación sin aislamiento ni disección de dichos nervios, y el empleo de técnicas quirúrgicas que minimicen o eviten disecciones o reparaciones agresivas sobre las citadas áreas y trayectos neurales para prevenir o evitar la inguinodinia. Para mejorar la comprensión y esclarecimiento de las dimensiones de la agresión tisular producida por cualquiera de las hernioplastias inguinales, se aportan 2 clasificaciones personales, inéditas e intuitivas. La 1. a con grupos y modelos de técnicas, dimensión y extensión de la invasividad (maxi, normo mini o mínimamente invasivas), y extensión y dimensión de la disectividad (maxi, normo y minidisectivas). Y la 2. a , de acuerdo con los grupos y modelos de técnicas, se detalla el riesgo probable o improbable de lesión neural en las respectivas ACRDIPCN: el riesgo neurolesivo en las hernioplastias. Sin duda, la experiencia, la pericia y la maestría técnica del cirujano, es la mejor profilaxis de la inguinodinia.

\section{Acrónimos}

DIPC: dolor inguinal posoperatorio crónico.

DIPA: dolor inguinal posoperatorio agudo.

DIPAS: dolor inguinal posoperatorio agudo somático.

DIPCS: dolor inguinal posoperatorio crónico somático.

DIPAN: dolor inguinal posoperatorio agudo neuropático.

DIPCN: dolor inguinal posoperatorio crónico neuropático.

ACRDIPCN: área crítica de riesgo de dolor inguinal posoperatorio crónico neuropático.

NIH: nervio iliohipogástrico.

NII: nervio ilioinguinal.

NGF: nervio genitofemoral.

RG: rama genital.

RF: rama femoral.

NF: nervio femoral.

NFCL: nervio femorocutáneo lateral.

NO: nervio obturador.

\section{Bibliografía}

1. Aasvang E, Kehlet H. Chronic postoperative pain: the case of inguinal herniorrhaphy. Br J Anaesthiol. 2005;95:69-76.

2. Bittner R, Arregui ME, Bisgaard T, Dudal M, Ferzli GS, Fitzgibbons RJ, et al. Guidelines for laparoscopic (TAPP) and endoscopic (TEP) treatment of inguinal hernia [International Endohernia Society (IEHS)]. Surg Endosc. 2011;25:2773-843.

3. Bittner R, Montgomery MA, Arregui E, Bansal V, Bingener J, Bisgaard T, et al. International Endohernia Society. Update of guidelines on laparoscopic (TAPP) and endoscopic (TEP) treatment of inguinal hernia (International Endohernia Society). Surg Endosc. 2015;29:289-321.

4. Murphy BL, Ibi DS, Zhang J, Habermann EB, Farley DR, Paley K. Trends of inguinal hernia repairs performed for recurrence in the United States. Surgery. 2018;163(2):343-50.

5. Gopal SV, Warrier A. Recurrence after groin hernia repair-revisited. Int J Surg. 2013;11:374-77.

6. Hecke O, Torrance N, Smith BH. Chronic pain epidemiology and its clinical relevance. BJA. 2013;113:13-8.

7. Lange JFM, Meyer VM, Voropai DA, Keus E, Wijsmuller AR, Ploeg RJ et al. The role of surgical expertise with regard to chronic postoperative inguinal pain (CPIP) after Lichtenstein correction of inguinal hernia: a systematic review. Hernia. 2016;20:349-56.
8. Dávila D. Dolor Inguinal. Profilaxis del dolor inguinal. Reparación preperitoneal por vía posterior abierta. Ponencia. II Curso de Actualización en Cirugía de Pared Abdominal. Sociedad Hispanoamericana de Hernia (SoHaH). 17 febrero 2017, Bilbao.

9. Annandale T. Case in which a reducible oblique and direct inguinal and femoral hernia existed on the same side were successfully treated for operation. Edinburgh Med J. 1876;27:1087.

10. Bassini E. Sulla cura radicale dell'ernia inguinale. Arch Soc Ital Chir. 1887;4:380-6.

11. van der Pool AE, Harlaar JJ, den Hoed PT, Weidema WF, van Veen $\mathrm{RN}$. Long-term follow-up evaluation of chronic pain after endoscopic total extraperitoneal repair of primary and recurrent inguinal hernia. Surg Endosc. 2010;24:1707-11.

12. Eklund A, Carlsson P, Rosenblad A, Montgomery A, Bergkvist L, Rudberg C. Swedish Mulricenter Trial of Hernia Repair by Laparoscopy (SMIL) Study Group. Br J Surg. 2010;97:600-8.

13. Koning GG, Wetterslev J, van Laarhoven CJ, Keus F. The Totally Extraperitoneal Method versus Lichtenstein's Technique for Inguinal Hernia Repair: A Systematic Review with Meta-Analyses and Trial Sequential of Randomized Clinical Trials. PLoS One. 2013;8 (1):e52599.

14. Anand KJS, Carr DB. The neuroanatomy, neurophysiology and neurochemistry of pain stress and analgesia in newborns and children. Pediatr Clin N Am. 1989;36:795-802.

15. Selye $\mathrm{H}$. The general adaptation syndrome and the diseases of adaptation. J Clin Endocrinol. 1946;6:117-84.

16. Tracey KJ. The inflammatory réflex. Nature. 2002;420:853-9.

17. Barton GM. A calculated response: control of inflammation by the innate immune system. J Clin Invest 2008;118:413-20.

18. Schroder K, Kanneganti TD, Shao F, Broz P. Mechanisms and Consequences of Inflammasome Activation. J Mol Biol. 2018;430: 131-2.

19. Gross O, Thomas CJ, Guarda G, Tschopp J. The inflammasome: an integrated view. Immunol Rev. 2011;243:136-51.

20. Shunke M, Schulte E, Schumacher U. Prometheus. Anatomía humana-Atlas. $2^{\mathrm{a}}$ ed. Madrid: Edit. Panamericana; 2007. pp. 64-5.

21. Reinpold W, Schroeder AD, Schroeder M, Berger C, Rohr M, Wehrenberg U. Retroperitoneal anatomy of the iliohypogastric, ilioinguinal, genitofemoral, and lateral femoral cutaneus nerve: consequences for prevention and treatment of chronic inguinodynia. Hernia. 2015;19:539-48.

22. Emeksiz S, Ozden H, Guven G. Effects of variable courses of inguinal on pain in patients undergoing Lichtenstein repair for inguinal hernia: preliminary results. Acta Chir Belg. 2013;113:196-202.

23. Bendavid R, Abrahamson J, Arregui ME, Flament JB, Phillips EH. Abdominal Wall Hernias. Principles and Management. Cap. 110113. $1^{\text {a }}$ ed. New York: Springer-Verlag; 2001. pp. 726-39.

24. Weijsmuller AR, Lange JF. Nerve identifying inguinal hernia repair: a surgical anatomical study. World J Surg. 2007;31:414-20.

25. Condon RE. La anatomía de la región inguinal y su relación con la hernia. En Nyhus LLM, Condon RE editores. Hernia. Cap. 2. $3^{\mathrm{a}}$ ed. Buenos Aires: Edit. Med. Panamericana;1991. pp. 39-77.

26. Rab M, Ebmer J, Dellon AL. Anatomic variability of the ilioinguinal and genitofemoral nerve: implications for the treatment of groin pain. Plast Reconstr Surg. 2001;108:1618-21.

27. Dávila D. La "invasividad" de las técnicas quirúrgicas en el tratamiento de las hernias de la región inguinal. Rev Hispanoam Hernia. 2016;4:97-107.

28. Ferzli GS, Edwards E, Al-Khoury G, Hardin RM. Postheniorrhaphy Groin Pain and How to Avoid it. Surg Clin N Am. 2008;88;203-16.

29. Wright RC, Sanders E. Inguinal neuritis is common in primary inguinal hernia. Hernia. 2011;15(4):393-8.

30. Bendavid R, Lou W, Grischkan D, Koch A, Petersen K, Morrison J, et al. A mechanism of mesh-related post-herniorrhaphy neuralgia. Hernia. 2016;20:357-65. 
31. Powell R, Johnston M, Smith WC, King PM, Chambers WA, Krukowski Z, et al. Psychological risk factors for chronic post-surgical pain after inguinal hernia repair surgery: a prospective cohort study. Eur J Pain. 2012;16:600-10.

32. Aasvang E, Kehlet H. Surgical manament of chronic pain after inguinal hernia repair. Br J Surg. 2005;92:795-801.

33. Cannon WB. Organization for Physiological Homeostasis. Physiological Reviews. 1928;9:399-443.

34. Blinnman T. Incisions do not simply sum. Surg Endosc. 2010;24:1746-51.

35. Carvahlo G. Can mathematic formulas help us with ours partients? Surg Endosc. 2011;25:336-7.

36. Zamora F, Dávila F, Dávila M. Daño tisular en cirugía laparoscópica. Rev Venez Cir. 2014;67:147-53.

37. Zannoni M, Nisi P, Iaria M, Luzietti E, Sianesi M, Viani L. Wide nervous section to prevent post-operative inguinodynia after prosthetic hernia repair: a single center experience. Hernia. 2015;19:565-70.

38. Heise CP, Starling JR. Mesh inguinodynia: a new clinical syndrome after inguinal herniorrhaphy? J Am Coll Surg. 1998;187:514-8.

39. Bansal VK, Misra MC, Babu D, Victor J, Kumar S, Sagar R, et al. A prospective, randomized comparison of long-term outcomes: chronic groin pain and quality of life following totally extraperitoneal (TEP) and transabdominal preperitoneal (TAPP) laparoscopic inguinal hernia repair. Surg Endosc. 2013;27:2373-82.

40. Álvarez Quintero R. Dolor inguinal crónico posoperatorio o inguinodinia. En Hernias de la Pared Abdominal. Tratamiento actual. Mayagoitia Gonzalez JC ed. Editorial Alfil S.A. $3^{\mathrm{a}}$ ed. Cap. 37, México,2015. pp 313-20.

41. Amid PK. Causes, prevention and surgical treatment of post-herniorrhaphy neuropathic inguinodynia: triple neurectomy with proximal end implantation. Hernia. 2004;8:343-9.

42. Moreno-Egea A. Borrás Rubio E. Neurectomía laparoscópica transabdominal retroperitoneal, selectiva y ambulatoria, para tratar el dolor neuropático inguinal refractario. Rev Hispanoam Hernia. 2014;02:67-71.

43. Kulasegaran S, Rohan M, Pearless L, Hulme-Moir M. Pre-peritoneal local anaesthetic does not reduce post-operative pain in laparoscopic total extra-peritoneal inguinal hernia repair: double-blinded randomized controlled trial. Hernia. 2017;21:879-85.

44. Apfelbaum JL, Ashburn MA, Connis RT, Gan TJ, Nickinovich DG, Caplan RA, et al. Practice guidelines for acute pain management in the perioperative setting: an updated report by the American Society of Anesthesiologists Task Force on Acute Pain Management. Anesthesiology. 2012;116:248-73.

45. Hanna MN, Ouanes JP, Tomas VG. Postoperative pain and other acute pain syndromes. In: Benzon HT, Rathmell JP, Wu CL, Turk DC, Argoff CE, Hurley RW, editors. Practical Management of Pain. 5th ed. Chapter 18. Philadelphia, PA: Elsevier Mosby; 2014.

46. Bademosi AT, Steeves J, Krunanithi S, Zalucki OH, Gormal RS, Liu S, et al. Trapping of Syntaxin 1a in Presynaptic Nanoclusters by a Clinically Relevant General Anesthetic. Cell Reports. 2018;22: 427-40.

47. Hallén M, Sevonius D, Westerdahl J, Gunnarsson U, Sandblom G. Risk factors for reoperation due to chronic groin posherniorraphy pain. Hernia. 2015;19:863-9.

48. Amid PK, Lichtenstein IL. Long-term result and current status of the Lichtenstein open tension-free hernioplasty. Hernia. 1998;2:89-94.

49. Rutkow IM, Robbins AW. The mesh plug-technique for recurrent groin herniorrhaphy: A nine-year experience of 407 repairs. Surgery. 1998;124:844-7.

50. Callesen T, Bech K, Kehlet H. Chronic pain after inguinal hernia repair - a prospective study after 500 operations. Br J Surg. 1999; 86:1528-31.

51. Acevedo A, López J, Villasí M, Aquiles S, León J. Síndrome de dolor inguinal crónico (SDIC). Rev Chil Cir. 2009;61:249-55.
52. Di Vita G, Milano S, Frazzetta M, Patti R, Palazzolo V, Barbera $\mathrm{C}$, et al. Tension-free hernia repair is associated with an increase in inflammatory response markers against the mesh. Am J Surg. 2000;180:203-7.

53. Günal Ö, Özer S, Gürleyik E, Bahçebasi T. Does the approach to the groin make a difference in hernia repair. Hernia. 2007;11:429-34.

54. Scheuermann U, Niebisch S, Lyros O, Jansen-Wilkeln B, Gockel I. Transabdominal preperitoneal (TAPP) versus Lichtenstein operation for primary inguinal hernia repair - A systematic review and meta-analysis of randomized controlled trials. BMC Surgery. 2017;17(1):55.

55. Koning GG, Wetterslev J, van Laarhoven, CJHM, Keus F. The Totally Extraperitoneal Method versus Lichtenstein's Technique for Inguinal Hernia Repair: A Systematic Review with Meta-Analyses and Trial Sequential of Randomized Clinical Trials. PLoS One. 2013;8(1):e52599.

56. Deysine M, Grimson RC, Soroff HS. Inguinal herniorrhaphy. Reduced morbidity by service standardization. Arch Surg. 1991;126: 628-30.

57. Dittrick GW, Ridl K, Kuhn JA. Routine ilioinguinal nerve excision in inguinal hernia repairs. Am J Surg. 2004;188:736-40.

58. Johner A, Faulds J, Wiseman SM. Planned ilioinguinal nerve excision for prevention of chronic pain after inguinal hernia repair: a meta-analysis. Surgery. 2011;150:534-42.

59. Smeds S, Lofstrom L, Eriksson O. Influence of nerve identification and the resection of nerves "at risk" on postoperative pain in open inguinal hernia repair. Hernia. 2010;14:265-70.

60. Dávila D, Trullenque R. Reparación de las hernias de la ingle por la vía preperitoneal posterior $<$ corta $>$. Técnica de Nyhus. En Carbonell F, editor. Hernia inguinocrural. Cap. 15, $1^{\mathrm{a}}$ ed. Madrid: Ethicon-J\&J; 2001. pp. 201-18.

61. Dávila D, García-Pastor P, Oviedo M, Carbonell F. Prótesis autoadhesiva por vía preperitoneal abierta (Nyhus modificado -técnica personal-) en el tratamiento de las hernias de la ingle. Rev Hispanoam Hernia. 2013;01:135-47.

62. Dávila D. La técnica de Nyhus y su repercusión en la evolución de la cirugía de la hernia inguinal. Rev Hispanoam Hernia. 2014;2:35-9.

63. Lichtenstein IL, Shore JM. Simplified repair of femoral and recurrent inguinal hernias by a "plug" technique. Am J Surg. 1974;128:439-44.

64. Carbonell F. Mitos de la cirugía en la hernia inguinal. ¿Fue Lichtenstein el inventor de la técnica que lleva su nombre? Revindicando a Zagdoun en la vieja Europa. ¿Quién fue el primero? Rev Hispanoam Hernia. 2015;3:75-80.

65. Gilbert AI. Suturless repair of inguinal hernia. Am J Surg. 1992; 163:331-5

66. Toy FK, Smoot RT. Toy-Smoot laparoscopic hernioplasty. Surg Laparosc Endosc. 1991;1:151-5.

67. Arregui ME, David CJ, Yucel O, Nagan RF. Laparoscopic mesh repair of inguinal hernia using a preperitoneal approach. A preliminary report. Surg Laparosc Endosc. 1992;2:53-8.

68. 68. Duluq JL. Traitement des hernies de l'aine par mise en place d'un patch prothétique sous-péritonéal en rétropéritonéoscopie. Cahiers Chir. 1991;79:15-6.

69. Daes J. La técnica totalmente extraperitoneal de vista extendida (e-TEP) para la reparación de la hernia inguinal. Cir Endosc. 2011;12:118-22.

70. Bucher P, Pugin F, Morel P. Single-port acces prosthetic repair for primary and incisional ventral hernias. Surg Endosc. 2011;25: 1921-5.

71. Domínguez LG, Gálvez R. Lesión de nervios periféricos en hernioplastia inguinal laparoscópica. Acta Med G Ángeles. 2006;4:123-8.

72. Verduzco E, Badami A, Sabido F. Robotic inguinal hernia repair eliminates the need for post-operative narcotics and demostrates lower post-operative pain scores. Hernia. 2018;22(Suppl 1):S94-S189. 
73. Dávila D, Oviedo M, Martín G, Lorenzo M, Carbonell F. ¿Es complejo reparar la hernia inguinal del prostatectomizado por vía retropúbica mediante el abordaje preperitoneal posterior abierto tipo Nyhus $<$ corto $>$ (técnica de Dávila)? Rev Hispanoam Hernia. 2015;3:5-15.

74. Vijan SS, Wall JC, Greenlee SM, Farley DR. Consequences of endoscopic inguinal hernioplasty with mesh on subsequent open radical prostatectomy. Hernia. 2008;12:415-9.

75. Tsivian A, Brodsky O, Shtricker A, Tsivian M, Benjamin S, Sidi AA. Urologic pelvic surgery following mesh hernia repair. Hernia. 2009;13:523-7.

76. Peeters E, Joniau S, van Poppel H, Miserez M. Case-matched analysis of outcome after open retropubic radical prostatectomy in patients with previous preperitoneal inguinal hernia repair. Br J Surg. 2012;99:431-5.

77. Han HJ, Kim CY, Choi SB, Kwak JM, Lee SI. Sigmoid colon fístula following totally extraperitoneal hernioplasty: an improper treatment for mesh infection or iatrogenic injury? Hernia. 2010;14: 655-8.

78. Meyer A, Blanc P, Balique JG, Kitamura M, Juan RT, Delacoste F et al. Laparoscopic totally extraperitoneal inguinal hernia repair: twenty-seven serious complications after 4565 consecutive operations. Rev Col Bras Cir. 2013;40:32-6.

79. Kouhia S, Vironen J, Hakala T, Paajanen H. Open Mesh Repair for inguinal Hernia is safer than Laparoscopic Repair or Open Nonmesh Repair: A Nationwide Registry Study of Complications. World J Surg. 2015;39:1878-84.

80. Nilsson H, Nordin P, Holmberg H, Nilsson E. Swedish hernia register: 25 years of prospective groin registry. Hernia. 2018;22 (Suppl. 1):S-169.

81. Negro P. Editorial. Rev Hispanoam Hernia. 2018;6(1):1-2.

82. Moreno-Egea A. ¿Por qué la hernioplastia inguinal bilateral laparoscópica (totalmente extraperitoneal) no ha conseguido mayor difusión después de dos décadas? Rev Hispanoam Hernia. 2013;1:3-4.

83. Caballero C. Enseñanza y formación en cirugía endoscópica de la pared abdominal. Rev Hispanoam Hernia. 2014;2:1-2.

84. Moreno Egea A. Unidades de Pared Abdominal y formación (en España). Rev Hispanoam Hernia. 2013;1:55-6.

85. Mayagoitia JC. LA enseñanza de la cirugía herniaria. Rev Hispanoam Hernia. 2013;01:133-4.

86. Rahr HB, Bendix J, Ahlburg P, Gjedsted J, Funch-Jensen P, Tønnesen E. Coagulation, inflammatory, and stress responses in a randomized comparison of open and laparoscopic repair of recurrent inguinal hernia. Surg Endosc. 2006;20:468-72.

87. Kokotovic D, Burcharth J, Helgstrand F, Gögenur I. Systemic inflammatory response after hernia repair: a systematic review. Langenbecks Arch Surg. 2017;402:1023-37.

88. Libiszewski M, Drozda R, Białecki J, Wieloch M, Hedayati M, Kuzdak K, et al. Assesment of inflammatory response intensity in early postoperative period in patients after hernioplasty operated on with classic stoppa method and videoscopic TEP method. Pol Przeg1 Chir. 2011;83:497-501.

89. Vats M, Pandey D, Saha S, Talwar N, Saurabh G, Andley M, et al. Assessment of systemic inflammatory response after total extraperitoneal repair and Lichtenstein repair for inguinal hernia. Hernia. 2017;21:65-71.

90. Hill AD, Banwell PE, Darzi A, Menzies-Gow N, Monson JR, Guillou PJ. Inflammatory markers following laparoscopic and open hernia repair. Surg Endosc. 1995;9:695-8.

91. Bender O, Levent Balci F, Yuney E, Saglam F, Ozdenkaya Y, Selim Sari Y. Systemic inflammatory response after Kugel versus laparoscopic groin hernia repair: A prospective randomized trial. Surg Endosc. 2009;23:2657-61.
92. Schwab R, Eissele S, Brückner UB, Gebhard, F, Becker HP. Systemic inflammatory response after endoscopic (TEP) vs Shouldice groin hernia repair. Hernia. 2004;8:226-32.

93. Gürleyik E, Gürleyik G, Cetinkaya F, Unalmiser S. The inflammatory response to open tension-free inguinal hernioplasty versus conventional repairs. Am J Surg. 1998;175:179-82.

94. Bulbuller N, Kirkil C, Godekmerdan A, Aygen E, Llhan YS. The comparison of Inflammatory Response and Clinical Results After Groin Hernia Repair Using Polypropilene or Polyester Meshes. Indian J Surg. 2015;77:283-7.

95. Di Vita G, Milano S, Patti R, Raimondo D, Di Bella G, D'Agostino P, et al. Cytokine modifications after tension-free hernioplasty or open conventional inguinal hernia repair. Am J Surg. 2001;181:487-91.

96. Donati M, Brancato G, Grosso G, Li Volti G, La Camera G, Cardì $\mathrm{F}$, et al. Immunological reaction and oxidative stress after light or heavy polypropylene mesh implantation in inguinal hernioplasty: A consort-prospective, randomized, clinical trial. Medicine (Baltimore). 2016;95(24):e3791.

97. Barros CM, Kimiko R, Machado A, Gerola LR, Salomao R. Citocinas y Dolor. Rev Bras Anestesiol. 2011;2:137-42.

98. Mantovani A, Dejana E. Cytokines as communication signals between leukocytes and endotelial cells. Immunol Today. 1989;10:370-5.

99. Vane JR, Angaard EE, Botting RM. Mechanisms of disease. Regulatory functions of the vascular endothelium. N Engl J Med. 1990;323:27-36

100. Palombo JD, Blackburn, Armour R. Endothelial cell factors and response to injury. Surg Gynecol Obst. 1991;173:505-18.

101. Lamkanfi M, Dixit VM. Mechanisms and functions of inflammasomes. Cell. 2014;157:1013-22.

102. Kuang J, Xie M, Wei X. The NALP3 inflammasome is requeride for collagen synthesis via the NF- $\kappa \beta$ pathway. Int J Mol Med. 2018;41:2279-87.

103. Yang ZF, Shen WZ, Lu C, Zheng WH, Xiao WF, Li XR. The study of three-nerve-reconognizing Lichtenstein procedure for inguinal hernia to reduce the risk of persistent inguinodynia. Hernia. 2015; (Suppl 2):S3-S194.

104. Sevonius D, Montgomery A, Smedberg S, Sandblom G. Chronic groin pain and physical disability after recurrent groin heria repair-impact of anterior and posterior mesh repair. Hernia. 2015;(Suppl 2):S3-S194.

105. Lange JF, Lange MM, Voropai DA, Van Tilburg MW, Pierie JP, Ploeg RJ, et al. Transrectus sheath extra-peritoneal procedure (TREPP) for inguinal hernia: the first 1000 patients. World J Surg. 2014.38;8:1922-8.

106. Bökkerink W, Van Laarhoven CJHM, Koning GG. Transrectus sheat preperitoneal mesh repair versus transinguinal preperitoneal procedure: a randomised clinical trial on inguinal hernia repair. Hernia. 2015;(Suppl 2):S3-S194.

107. Dávila D, Medrano J, del Rosal R, Molina E, Diestro G, Calvo MA et al. Aspectos anatomo-quirúrgicos y tácticos en la herniorrafia por vía preperitoneal de Nyhus. Ponencia. XVII Congreso Nacional de Cirugía. Asociación Española de Cirujanos. Madrid; 1988.

108. Dávila D, Trullenque R. Herniorrafia por vía Preperitoneal. En Avances, Controversias y Actualizaciones. Cirugía General y del Aparato Digestivo. Tomo I. Edit. Tamames S. y Martínez C. Emisa editores. Madrid; 1994. pp. 113-27.

109. Dávila D, Oviedo M, Roig JV. En Técnicas protésicas posteriores. Técnicas preperitoneales abiertas. Cirugía de la Pared Abdominal. Guías Clínicas de la Asociación Española de Cirujanos. Morales S, Barreiro F, Hernández P, Feliu X, editores. $2^{\mathrm{a}}$ ed. Madrid: Arán Ediciones, S.L.; 2013. pp. 363-83.

110. Walsh PC, Retik AB, Wein AJ. Chronic orchialgia. In: Campbell's Urology. 8th. Chapter 44. Ed. Saunders; 2002. pp.1582-3. 